\title{
Cell Death of Nicotiana benthamiana Is Induced by Secreted Protein NIS1 of Colletotrichum orbiculare and Is Suppressed by a Homologue of CgDN3
}

\author{
Kae Yoshino, ${ }^{1}$ Hiroki Irieda, ${ }^{1}$ Fumie Sugimoto, ${ }^{1}$ Hirofumi Yoshioka, ${ }^{2}$ Tetsuro Okuno, ${ }^{1}$ and \\ Yoshitaka Takano' \\ ${ }^{1}$ Graduate School of Agriculture, Kyoto University, Kyoto, Japan; ${ }^{2}$ Graduate School of Bioagricultural Sciences, Nagoya \\ University, Nagoya, Japan
}

Submitted 20 December 2011. Accepted 23 January 2012.

\begin{abstract}
Colletotrichum orbiculare, the causal agent of cucumber anthracnose, infects Nicotiana benthamiana. Functional screening of $C$. orbiculare cDNAs in a virus vector-based plant expression system identified a novel secreted protein gene, NIS1, whose product induces cell death in $N$. benthamiana. Putative homologues of NIS1 are present in selected members of fungi belonging to class Sordariomycetes, Dothideomycetes, or Orbiliomycetes. Green fluorescent protein-based expression studies suggested that NIS1 is preferentially expressed in biotrophic invasive hyphae. NIS1 lacking signal peptide did not induce NIS1-triggered cell death (NCD), suggesting apoplastic recognition of NIS1. NCD was prevented by virus-induced gene silencing of $S G T 1$ and $H S P 90$, indicating the dependency of NCD on SGT1 and HSP90. Deletion of NIS1 had little effect on the virulence of $C$. orbiculare against $N$. benthamiana, suggesting possible suppression of NCD by $C$. orbiculare at the postinvasive stage. The $C g D N 3$ gene of $C$. gloeosporioides was previously identified as a secreted protein gene involved in suppression of hypersensitive-like response in Stylosanthes guianensis. Notably, we found that NCD was suppressed by the expression of a CgDN3 homologue of $C$. orbiculare. Our findings indicate that $C$. orbiculare expresses NIS1 at the postinvasive stage and suggest that NCD could be repressed via other effectors, including the $\mathrm{CgDN3}$ homologue.
\end{abstract}

The first tier of plant defense involves recognition of conserved microbial molecules (microbe-associated molecular patterns [MAMPs]). MAMP-triggered immunity (MTI) is a conserved ancestral immune system against a broad range of microbial pathogens. However, MTI can be suppressed by virulence factors, called effectors, secreted by microbes. Plants respond to such suppression with a second-tier defense system called effector-triggered immunity (ETI), which involves resistance (R) proteins (Boller and Felix 2009; Chisholm et al. 2006). ETI is typically associated with localized cell death known as hypersensitive response (HR). In turn, pathogens likely have developed ways of manipulating or evading this second tier of defense. To escape from ETI, pathogens lose or

Corresponding author: Y. Takano; E-mail: ytakano@kais.kyoto-u.ac.jp; Fax +81-75-753-6131.

* The $\boldsymbol{e}$-Xtra logo stands for "electronic extra" and indicates that two supplementary figures and one supplementary table are published online. alter effectors recognized by plants and gain new effectors, perhaps through horizontal gene flow and pathoadaptation (Jones and Dangl 2006; Ma et al. 2006). However, there are several examples of suppression of ETI by other effectors (Jones and Dangl 2006; Houterman et al. 2008; Rosebrock et al. 2007), suggesting alternative ways of pathogens to cope with ETI.

For example, AvrPtoB, an effector of a plant-pathogenic bacterium, Pseudomonas syringae pv. tomato, suppresses ETI triggered by an $F E N$-encoded kinase. The C-terminal region of AvrPtoB is an E3 ubiquitin ligase, and ubiquitinates FEN and promotes its degradation in a proteasome-dependent manner (Rosebrock et al. 2007). It has also been recently reported that the fungal effector, Avr1, of Fusarium oxysporum f. sp. lycopersici has the ability to suppress $R$-gene-mediated resistance (Houterman et al. 2008). Avr1 is a small protein secreted by $F$. oxysporum f. sp. lycopersici during colonization of xylem vessels of the tomato and is recognized as an avirulence (AVR) protein by the tomato $R$ genes $I$ and $I-1$. Avr2 and Avr3 are AVR effectors that are recognized by cognate tomato $R$ genes $I-2$ and $I-3$, respectively. Avr1 suppresses the ability of the $I-2$ and $I-3 R$ genes to confer resistance against $F$. oxysporum $\mathrm{f}$. sp. lycopersici race 1 strains despite the secretion of Avr2 and Avr3 by these strains (Houterman et al. 2008). Thus, Avr1 is the first cloned fungal effector that suppresses $R$-gene-mediated disease resistance in planta, although it remains to be elucidated how Avr1 suppresses ETI triggered by Avr2 and Avr3 at the molecular level.

It has also been shown that the Phytophthora infestans RXLR effector, AVR3a, has the ability to suppress cell death caused by the elicitin INF1 (Bos et al. 2006). AVR3a interacts with and stabilizes the host U-box E3 ligase, CMPG1, which is required for INF1-dependent cell death (Bos et al. 2010). AVR3a also suppresses cell death triggered by an ETI response such as Cf-9/Avr9 and Pto/AvrPto (Gilroy et al. 2011). Furthermore, testing of 169 candidate effectors of $P$. sojae revealed that most could suppress cell death triggered by BAX, effectors (Avh238 and Avh241), or INF1 (Wang et al. 2011). These surprising data suggest that $P$. sojae has a large set of effectors that can suppress multiple cell death events triggered via recognition of secreted proteins of pathogens by plants. The necrosis and ethylene-inducing protein 1-like proteins (NLP) are present in many pathogenic bacteria, fungi, and oomycetes that generally induce cell death in dicot plants (Pemberton and Salmond 2004). NLP are regarded as apoplastic effectors having phytotoxic activity (de Jonge et al. 2011), and the crystal structure of NLP from the necrotroph Pythium aphanidermatum 
revealed structural homology to cytolytic actinoporins (Ottmann et al. 2009), suggesting that the NLP effectors insert into the host membrane to form pores. It has been reported that an RXLR effector, SNE1 (suppressor of necrosis 1) of Phytophthora infestans, suppresses the NLP-induced cell death as well as multiple ETI responses (Kelley et al. 2010). These findings, mainly derived from studies of the Phytophthora spp., suggest that plant pathogens likely secrete multiple cell-death-inducing proteins regarded as AVR effectors, elicitins possibly regarded as pathogen-associated molecular pattern (PAMP)-related proteins, or phytotoxic effectors such as NLP during their host plant infection. And, importantly, the findings provide the examples that cell death caused by these proteins can be suppressed by other effector proteins.

Anthracnose fungi belonging to the genus Colletotrichum cause severe diseases on a wide range of crop and ornamental plants (Bailey and Jeger 1992). The majority of Colletotrichum spp. use a hemibiotrophic infection strategy during postinvasive growth, in which these pathogens initially grow biotrophically in living host cells before switching to a destructive necrotrophic phase of infection (Perfect et al. 1999). The Colletotrichum spp. can be cultured axenically and genetically modified by stable transformation. This greatly facilitates mutational analysis and assessment of gene function using targeted gene disruption, which has led the identification of many genes involved in pathogenicity in the Colletotrichum spp. (Asakura et al. 2009; Lee et al. 2003; Miyara et al. 2008; Perfect et al. 1999; Sakaguchi et al. 2010; Tanaka et al. 2009; Zhao et al. 2007). A set of secreted protein genes was also identified in several $\mathrm{Col}$ letotrichum spp. by expressed sequence tag analysis or the screening by yeast signal sequence trap (Bhadauria et al. 2011;

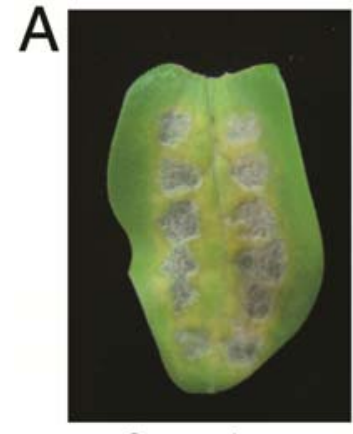

Cucumber

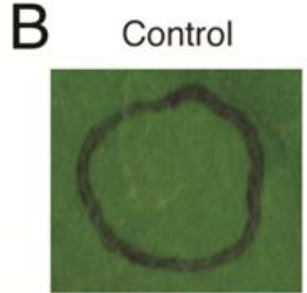

Fig. 1. Culture filtrate of Colletotrichum orbiculare induces cell death in a susceptible plant, Nicotiana benthamiana. A, C. orbiculare infects and develops necrotic lesions on both cucumber and $N$. benthamiana. Detached cucumber cotyledon and $N$. benthamiana leaf were spot inoculated with conidial suspension of $C$. orbiculare and inoculated leaves were incubated for 6 days. B, Infiltration of $C$. orbiculare culture filtrate into $N$. benthamiana. The $C$. orbiculare wild-type strain 104-T was grown in liquid media and its culture filtrate was recovered. The culture filtrate was infiltrated directly into $N$. benthamiana (-H.T.) or exposed to $95^{\circ} \mathrm{C}$ for $5 \mathrm{~min}(+\mathrm{H} . \mathrm{T}$.) before infiltration. Liquid medium alone was used as a control. Black circles indicate infiltrated regions. The photograph was taken 9 days after the infiltration. Photographs are representative of three independent experiments, and similar results were obtained in each experiment.
Kleemann et al. 2008; Krijger et al. 2008; Miyara et al. 2008). However, there is still little information on secreted proteins of the Colletotrichum spp. that induce cell death in planta and, conversely, suppress cell-death responses.

Here, we report that a plant-pathogenic fungus, Colletotrichum orbiculare, secretes a protein that has the activity to induce cell death in Nicotiana benthamiana, a plant susceptible to this pathogen. C. orbiculare (syn. C. lagenarium) causes anthracnose disease of cucumber, and this fungal pathogen forms a specific infection structure called an appressorium, which is pigmented with melanin. Interestingly, it has been found that at least two natural isolates of $C$. orbiculare infect $N$. benthamiana, in addition to the natural host of $C$. orbiculare, the cucumber (Shen et al. 2001; Takano et al. 2006). Because an efficient virus-induced gene silencing (VIGS) method has been established for $N$. benthamiana (Lu et al. 2003), this pathosystem provides the advantages to study plant-fungal pathogen interactions bidirectionally at molecular level.

To ask whether $C$. orbiculare expresses secreted proteins that can trigger cell death in the susceptible plant $N$. benthamiana, we performed functional screening of $C$. orbiculare cDNAs using a Potato virus $X(\mathrm{PVX})$-based expression vector in $N$. benthamiana (Takken et al. 2000). Screening identified a novel secreted protein gene named necrosis-inducing secreted protein 1 (NISI) whose expression strongly induced cell death in N. benthamiana. The presence of NIS1 is limited to a part of filamentous fungi belonging to class Sordariomycetes, Dothideomycetes, or Orbiliomycetes. A promoter assay using green fluorescent protein (GFP) suggested that NIS1 is preferentially expressed in invasive biotrophic hyphae of $C$. orbiculare. NIS1-induced cell death depends on SGT1 and HSP90, which are components of an $R$-gene-dependent ETI in $N$. benthamiana but does not depend on RAR1. The deletion of NIS1 had little effect on pathogenicity of $C$. orbiculare on $N$. benthamiana, implying that $C$. orbiculare suppresses NIS1-mediated cell death in $N$. benthamiana, possibly by employing other effectors. $C g D N 3$ was previously identified as a pathogenicity-related gene in $C$. gloeosporioides isolate that infects Stylosanthes guianensis (Stephenson et al. 2000). CgDN3 encodes a small protein with a signal peptide, and the inoculation assay of the $C g D N 3$ knockout mutants suggested that the mutants elicited a local HR-like response by the host plant, implying the involvement of $\mathrm{CgDN3}$ in suppression of the HR-like response (Stephenson et al. 2000). In this report, we also show that a $C g D N 3$ homologue of $C$. orbiculare can suppress NIS1induced cell death.

\section{RESULTS}

\section{C. orbiculare NIS1 encodes a putative secreted protein} that induces necrotic lesions in $N$. benthamiana.

Inoculation of $C$. orbiculare results in necrotic lesions on $N$. benthamiana as well as its natural host, cucumber (Fig. 1A). When we prepared the filtrates from mycelial cultures of $C$. orbiculare grown in liquid nutrient media and infiltrated this into $N$. benthamiana, we found that the culture filtrates induced yellowish lesions in the treated leaf areas (Fig. 1B). Heat treatment abolished the ability of culture filtrates to induce these lesions (Fig. 1B). These results suggest that $C$. orbiculare secretes a proteinaceous molecule or molecules, at least during vegetative mycelial growth, that induce yellowish lesions in $N$. benthamiana by triggering cell death.

To identify a putative secreted protein that triggers cell death in $N$. benthamiana, we performed functional screening of $C$. orbiculare cDNAs in $N$. benthamiana. Takken and associates (2000) developed a functional cloning strategy based on a binary PVX expression vector and applied it to express pathogen 
genes in planta. We synthesized cDNAs from mRNA extracted from $C$. orbiculare conidia incubated on a glass surface and $N$. benthamiana leaves infected with $C$. orbiculare (details below) and directionally cloned them into pSfinx in the sense orientation. We screened 6,669 cDNAs by toothpick inoculation of $N$. benthamiana leaves using Agrobacterium tumefaciens carrying recombinant pSfinx and the cDNA. Four cDNAs (11097, 14051, 40112, and 44011) induced yellowish or necrotic lesion formation around the inoculation sites in N. benthamiana (Fig. 2A and B; data not shown). All four clones contained distinct open reading frames (ORF). A homology search for the sequences obtained suggested that 11097 cDNA encodes a ubiquitin protein of $N$. benthamiana. The 14051 cDNA encodes a protein highly homologous to a predicted protein (FG11622.1) of Gibberella zeae (F. graminearum). The 40112 cDNA encodes a protein homologous to fungal bZIP proteins, which are basic transcription factors. SignalP analysis suggested that these three cDNA clones are unlikely secreted protein genes, although we cannot exclude a possibility of secretion via an alternative secretion pathway. SignalP search revealed that the 44011 cDNA encodes a protein containing a putative extracellular signal. This result suggests that 44011 cDNA encodes a secreted protein of $C$. orbiculare and probably has the ability to induce necrotic lesion formation in $N$. benthamiana.

The entire region of the gene corresponding to the 44011 cDNA was amplified by polymerase chain reaction (PCR) using 104-T genome DNA as a template. The ORF is composed of two exons and one intron, and encodes a protein composed of 162 amino acids (Fig. 2C; data not shown). We focused on this putative secreted protein of $C$. orbiculare, NIS1, which has no conserved domain in its amino acid sequences, and genes showing homology to NIS1 are present in a limited group of fungi. They are present in the genome sequences of $C$. higginsianum, C. graminicola, Metarhizium anisopliae, Nectria haematococca, Trichoderma virens, $T$. atroviride, $T$. reesei, $G$. zeae, F. oxysporum, M. acridum, and Magnaporthe oryzae that belong to Sordariomycetes; and Mycosphaerella graminicola, Phaeosphaeria nodorum, Pyrenophora teres, and P. triticirepentis that belong to Dothideomycetes (Fig. 2C; Supplementary Fig. S1). On the other hand, the NIS1 homologue was not detected in Neurospora crassa and Verticillium albo-atrum that belong to Sordariomycetes and Leptosphaeria maculans belonging to Dothideomycetes. The NIS1 homologue is also present in a nematode-trapping fungus, Arthrobotrys oligospora, that belongs to Orbiliomycetes.
A
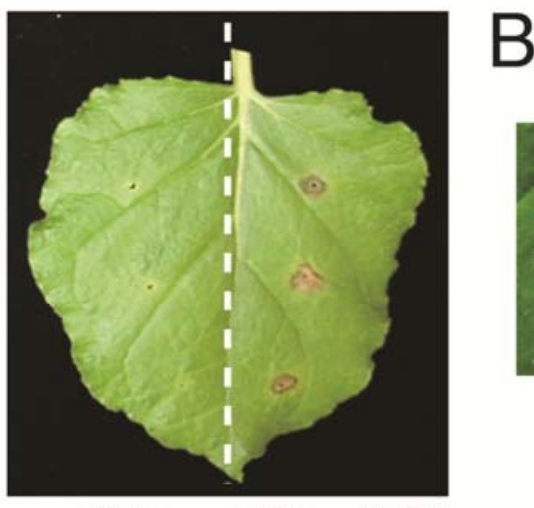

pSfinx pSfinx-NIS1

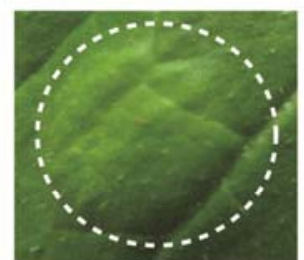

pSfinx

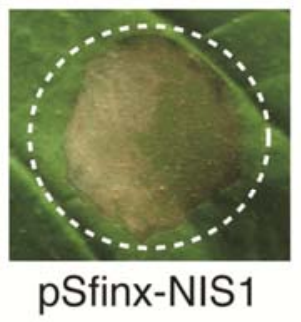

pSfinx-NIS1
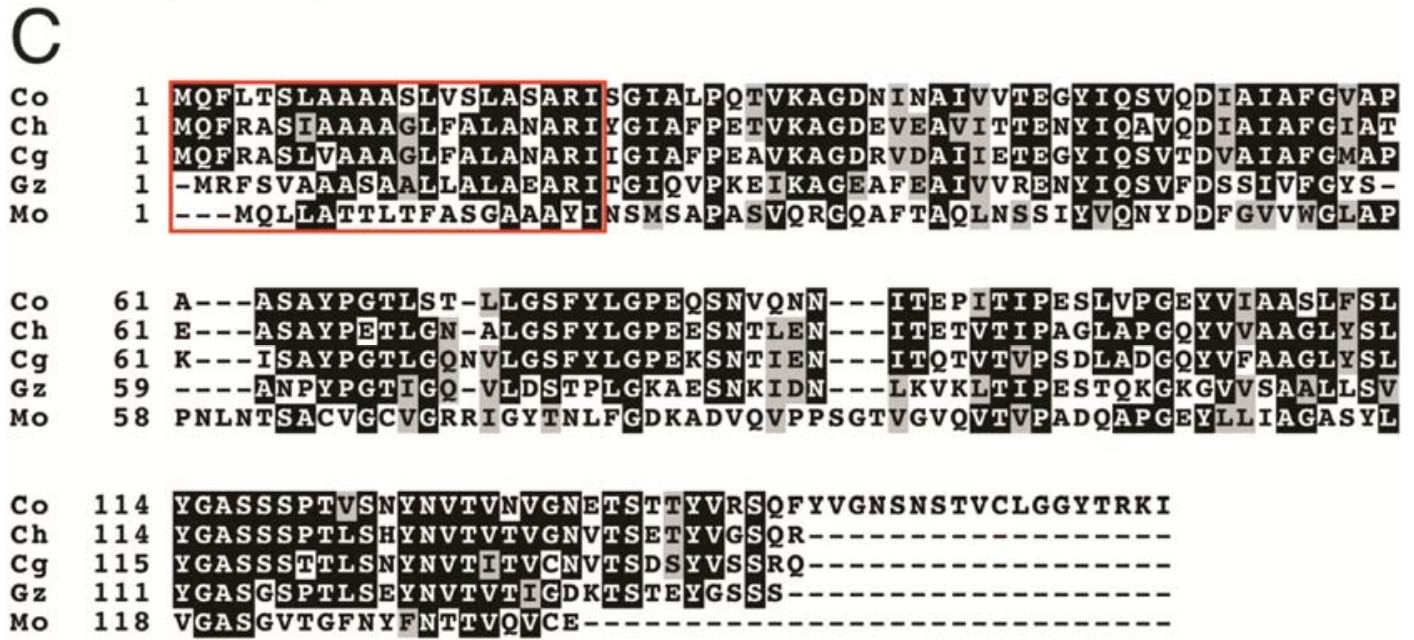

Fig. 2. Identification of the necrosis-inducing secreted protein 1 (NIS1) gene by functional screening of Colletotrichum orbiculare cDNAs in Nicotiana benthamiana. A, Agrobacterium tumefaciens carrying cDNA of $C$. orbiculare was inoculated onto $N$. benthamiana using the toothpick method to screen for cell-death-inducing factors. Screening identified NIS1, which caused lesions on N. benthamiana. A. tumefaciens carrying pSfinx-NIS1 was toothpick inoculated onto $N$. benthamiana (right). A. tumefaciens carrying pSfinx vector was inoculated as a control (left). The photograph was taken at 7 days postinoculation (dpi). B, A. tumefaciens cells containing pSfinx or pSfinx-NIS1 were infiltrated into $N$. benthamiana. The photograph was taken at 7 dpi. Dotted lines indicate the infiltration sites. C, Amino acid sequence alignment of NIS1 of C. orbiculare (Co) with NIS1 homologues in other fungal pathogens. NIS1 homologues used for the alignment included C. higginsianum (Ch), C. graminicola (Cg), Gibberella zeae (Gz), and Magnaporthe oryzae (Mo). Amino acid sequences were aligned using the ClustalW program (Thompson et al. 1994). Identical amino acids are indicated as white letters on a black background, similar residues are indicated on a gray background, and gaps introduced for alignments are indicated by hyphens. The putative signal peptide sequence is indicated by a red open box. 
The inducing activity of mycelial culture filtrates depends on secreted NIS1.

Because NIS1 has a putative signal peptide, we investigated whether NIS1 is secreted from $C$. orbiculare cells. Transgenic C. orbiculare expressing HA-tagged NIS1 was generated and incubated in liquid complete media. We found that HA-tagged NIS1 was detected in the transformant as a band larger than the size estimated based on the amino acid sequence of NIS1HA (17.9 kDa for NIS1-HA and $15.8 \mathrm{kDa}$ for matured NIS1HA lacking the signal peptide) (Fig. 3A). Western blot analysis detected NIS1-HA in the culture filtrate of the transformant (Fig. 3A). In contrast, when HA-tagged NIS1 lacking a signal peptide (NIS1 $\Delta \mathrm{SP}$ ) was expressed in $C$. orbiculare, NIS1 $\Delta \mathrm{SP}$ was detected in fungal mycelia at the expected molecular size but was not detected in the culture filtrate (Fig. 3A). These
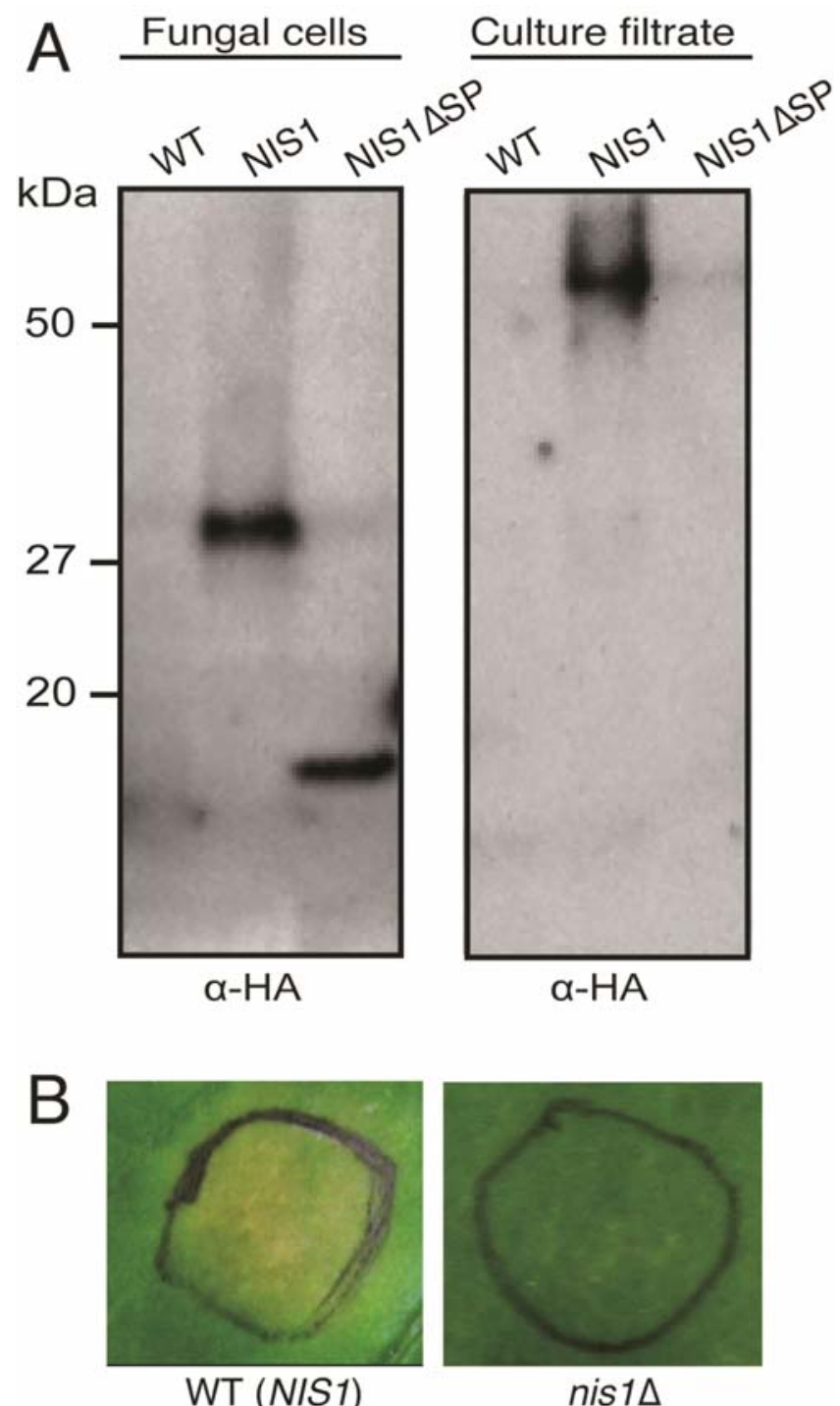

Fig. 3. Cell-death-inducing activity depends on secreted necrosis-inducing secreted protein 1 (NIS1) in the culture filtrate. A, Western blot analysis of protein extracts of fungal mycelia and of culture filtrates from the wildtype (WT) strain, the WT expressing NIS1-HA (NIS1), and the WT expressing NIS $1 \Delta$ SP-HA (NIS1 $\Delta$ SP). Fungal strains were grown in complete medium liquid medium for $48 \mathrm{~h}$. Protein extracts were analyzed by sodium dodecyl sulfate polyacrylamide gel electrophoresis using anti-HA antibody. B, Culture filtrate from WT or the nis $1 \Delta$ strain, generated by targeted disruption, was infiltrated into the Nicotiana benthamiana leaves. The photograph was taken at 9 days postinoculation. Black circles indicate the infiltrated regions. Photographs are representative of three independent experiments, and similar results were obtained in each experiment. data suggest that NIS1 is secreted from mycelial cells of $C$. orbiculare grown in liquid culture. Also, the detected NIS1 in the culture filtrate was larger in size than that detected in mycelial cells (Fig. 3A).

To verify whether NIS1 secreted from $C$. orbiculare is responsible for the culture filtrate activity that induces the yellowish symptom on Nicotiana benthamiana, we generated knockout mutants of NISI in C. orbiculare by the targeted gene disruption method (Supplementary Fig. S2). The nis1 null (nis $1 \Delta$ ) mutant and the wild type (WT) were grown in liquid media for 2 days, and culture filtrates were prepared from the liquid culture of each strain. Infiltration of the culture filtrate of the WT induced the yellowish symptom in N. benthamiana but the culture filtrate of nis $1 \Delta$ did not induce it (Fig. 3B). These findings indicate that the ability of the culture filtrate of $C$. orbiculare to induce the yellowish symptom depends on the NIS1-encoded secreted protein.

Next, we investigated the expression pattern of NIS1 during the plant infection process. The putative promoter region of NIS1 (1.5 kb upstream region) was fused to GFP, and this promoter reporter construct (NIS1p-GFP) was introduced into the WT of $C$. orbiculare. In transformants carrying NIS1p-GFP, the GFP signal was hardly detected in ungerminating conidia (Fig. 4). We detected the faint GFP signal in appressoriumforming conidia on the glass (Fig. 4). However, the signal was clearly induced in bulbous invasive hyphae that developed inside $N$. benthamiana and cucumber at the biotrophic stage, suggesting preferential expression of NIS1 in biotrophic invasive hyphae (Fig. 4, 3 days postinoculation [dpi]). The intensity of the GFP signal was reduced in necrotrophic invasive hyphae (Fig. 4, 5 dpi). The GFP signal was also detected in vegetative mycelia of the transformants (data not shown), which is consistent with the NIS1-dependent activity of mycelial culture filtrate to induce a yellowish symptom in N. benthamiana (Fig. 3B).

\section{NIS1-induced cell death-related regions of NIS1.}

We performed a series of experiments to investigate regions of NIS1 that are critical for the NIS1-induced cell death (NCD) in $N$. benthamiana. First, we determined whether NIS1 is recognized in the apoplasts of $N$. benthamiana. To assess this, we generated HA-tagged full-length NIS1 and HA-tagged NIS1 lacking the signal peptide (NIS1 $\Delta$ SP) with a Cauliflower mosaic virus (CaMV) 35S promoter and introduced each construct into Agrobacterium spp. Infiltration of each recombinant Agrobacterium sp. into $N$. benthamiana was performed. We detected both NIS1 and NIS1 $\Delta$ SP in each infiltrated $N$. benthamiana at similar quantitative levels, although NIS1 but not NIS1 $\Delta$ SP was detected as a band larger than that expected based on its amino acid number (Fig. 5A, Western blot analysis). Infiltration of the recombinant Agrobacterium sp. with NIS1 induced necrotic lesions in N. benthamiana but Agrobacterium spp. with NIS1 $\triangle \mathrm{SP}$ did not induce lesions (Fig. 5A, agroinfiltration assay). This result suggests that apoplastic recognition of NIS1 causes NCD in N. benthamiana.

We also generated two C-terminal deletion constructs of NIS1 with HA-NIS1 lacking $60 \mathrm{C}$-terminal amino acids (NIS1 $\triangle$ C60) and NIS1 lacking $30 \mathrm{C}$-terminal amino acids (NIS1 $\Delta \mathrm{C} 30$ ) - and investigated their Agrobacterium sp.-mediated expression in $N$. benthamiana, as described for analysis of NIS1 $\Delta$ SP. NIS1 $\Delta$ C30 showed a severe reduction in activity but still induced slight lesions (Fig. 5B, agroinfiltration assay). NIS1 $\Delta$ C60 completely lacked the inducible activity (Fig. 5B, agroinfiltration assay). Western blot analysis showed that NIS1 $\Delta$ C30 and NIS1 $\Delta$ C60 accumulated to the same extent as NIS1. NIS1 $\Delta \mathrm{C} 30$ and NIS1 $1 \Delta \mathrm{C} 60$ were detected at the size expected based on their molecular weight, which is in contrast 
with NIS1 (Fig. 5B, Western blot analysis), suggesting possible modification of NIS1 in the C-terminal 30-amino-acid region.

We further investigated whether putative NIS1 homologues of other pathogens cause necrotic lesions in $N$. benthamiana (Fig. 5C). We cloned the putative homologues of $C$. higginsianum and Magnaporthe oryzae, designated ChNISl and MoNIS1, respectively. We then constructed 35S-driven ChNIS1$\mathrm{HA}$ and MoNIS1-HA and investigated their activities. As a result, ChNIS1-HA but not MoNIS1-HA induced necrotic lesions (Fig. 5C).

\section{Requirement of SGT1 and HSP90 but not RAR1 for NCD.}

It is known that SGT1, RAR1, and HSP90 play central roles in the $\mathrm{R}$ protein-mediated $\mathrm{HR}$ by stabilizing the $\mathrm{R}$ protein complex (Shirasu 2009; Shirasu and Schulze-Lefert 2003). To test the possibility that NCD depends on SGT1, RAR1, or HSP90, we performed a VIGS assay against these genes. A Tobacco rattle virus construct carrying each gene was agroinoculated into $N$. benthamiana to generate silenced plants. Subsequently, an Agrobacterium sp. carrying NIS1 was infiltrated into each silenced plant. NIS1 failed to induce necrotic cell death in both SGT1- and HSP90-silenced plants, whereas NIS1 induced cell death in RARl-silenced plants (Fig. 6). Thus, SGT1 and HSP90 are required for NCD, whereas RAR1 is not.

\section{Pathogenicity test of the nis $1 \Delta$ mutants.}

To investigate whether loss of NIS1 affects the infection process of $C$. orbiculare toward $N$. benthamiana, we investigated the virulence of the $C$. orbiculare nis $1 \Delta$ mutants on $N$. benthamiana. The nis $1 \Delta$ mutants showed a colony morphology identical to that of the WT. The mutants formed melanized appressoria on glass, as did the WT (Fig. 7A). We investigated the pathogenicity of the nis $1 \Delta$ mutants on $N$. benthamiana and compared it with the pathogenicity of the WT. The inoculation assay on detached $N$. benthamiana leaves revealed that both the WT and nis $1 \Delta$ developed lesions on $N$. benthamiana to the same extent (Fig. 7B). The finding that the nis $1 \Delta$ mutants did not alter virulence on $N$. benthamiana suggested a possibility that NCD was suppressed in $N$. benthamiana during infection by $C$. orbiculare, although there was a possibility that the amount of NIS1 secreted by $C$. orbiculare during infection was insufficient to trigger NCD in $N$. benthamiana. We also found that the nis $1 \Delta$ mutants showed pathogenicity on the host plant, cucumber, the same as the WT (Fig. 7C).

\section{A CgDN3 homologue of $C$. orbiculare suppresses NCD.}

The phenotypic analysis of the nis $1 \Delta$ mutants suggested a possible suppression of NCD in N. benthamiana where $C$. orbiculare infects. Therefore, we hypothesized that NCD is suppressed by unidentified effectors of $C$. orbiculare. Although there is little information on cell death suppressors of the Colletotrichum spp., one possible candidate gene named $\mathrm{CgDN} 3$ was previously identified in a $C$. gloeosporioides isolate that infects $S$. guianensis (Stephenson et al. 2000). CgDN3 encodes a protein of 74 amino acids with a signal peptide (Fig. 8A). Interestingly, $C g D N 3$ knockout mutants were unable to infect and elicited a local HR-like response by the host plant (Stephenson et al. 2000), suggesting a possibility that the $C g D N 3$-encoded secreted protein can suppress the HR-like response. We identified a homologue of the $C g D N 3$ gene in $C$. orbiculare, indicating that $C g D N 3$ is not unique in $C$. gloeosporioides but shared in $C$. orbiculare (Fig. 8A). The $C g D N 3$ homologue of $C$. orbiculare, designated $C o D N 3$, encodes a 73-amino-acid protein with a signal peptide, $72.6 \%$ identity, and $94.5 \%$ similarity to $\mathrm{CgDN} 3$. To investigate a possibility that CoDN3 can prevent NCD, we generated HA-tagged full-length CoDN3 (CoDN3)
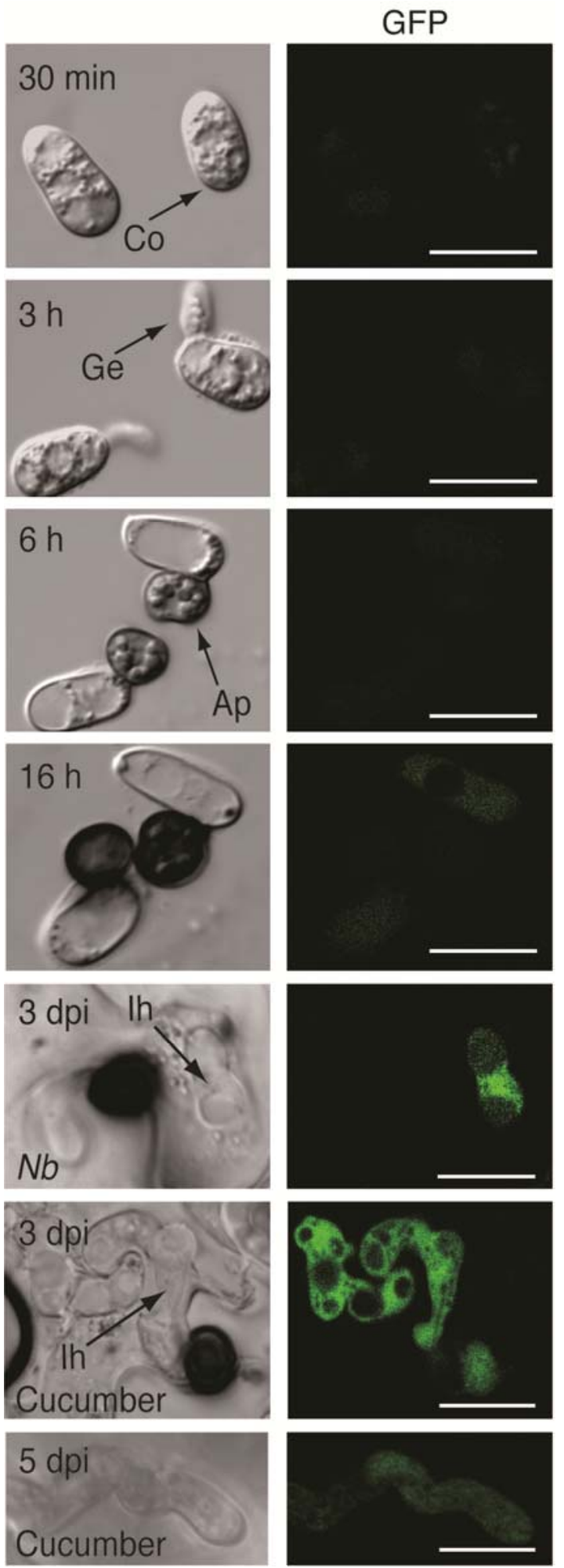

Fig. 4. Green fluorescent protein (GFP)-based reporter assay for expression of the necrosis-inducing secreted protein 1 (NIS1) gene. The transcriptional pattern of the NIS1 gene in the infection process of Colletotrichum orbiculare. Conidia from a $C$. orbiculare wild-type strain carrying the NIS1 promoter-GFP fusion gene (NIS1p-GFP) were incubated on glass for $30 \mathrm{~min}$ and 3,6 , and $16 \mathrm{~h}$. To observe NIS1 expression in invasive hyphae, a conidial suspension of the strain was inoculated onto the lower surfaces of both Nicotiana benthamiana leaves or cucumber cotyledons, and the inoculated plants were observed at 3 or 5 days postinoculation. Bars $=10 \mu \mathrm{m}$. Co, conidium; Ge, germ tube; Ap, appressorium; Ih, invasive hypha. 

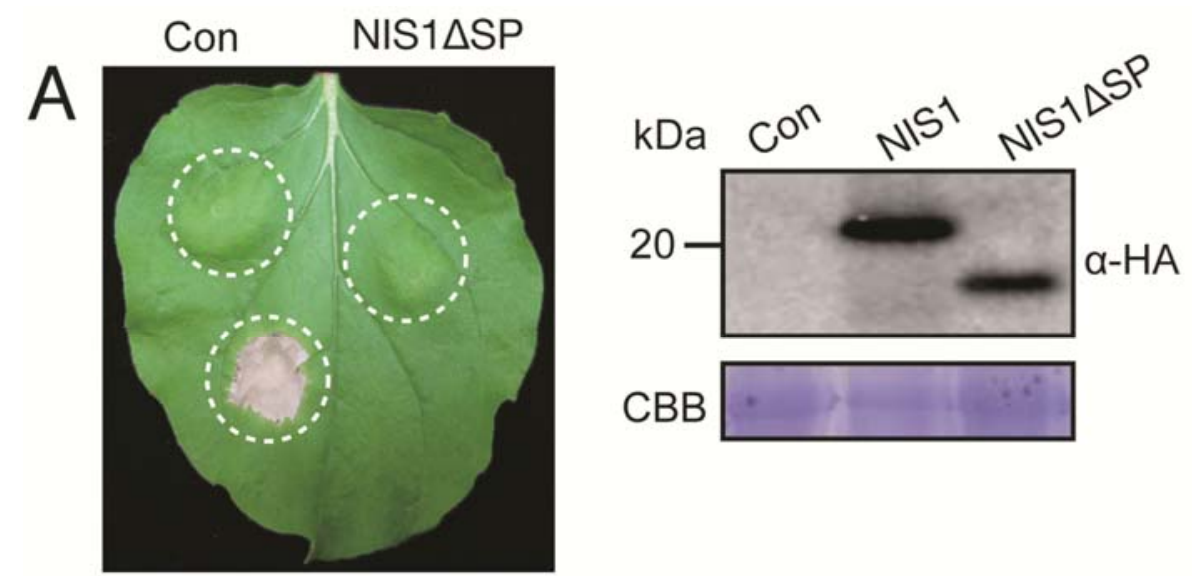

NIS1
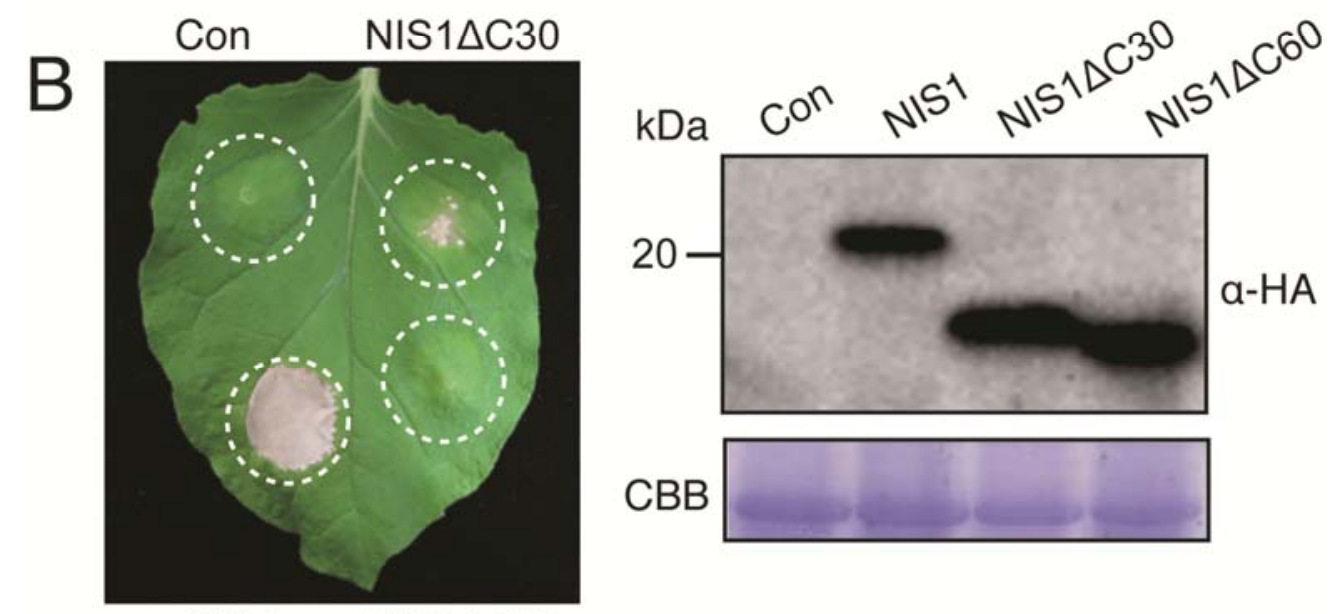

NIS1 NIS1 $\triangle \mathrm{C} 60$
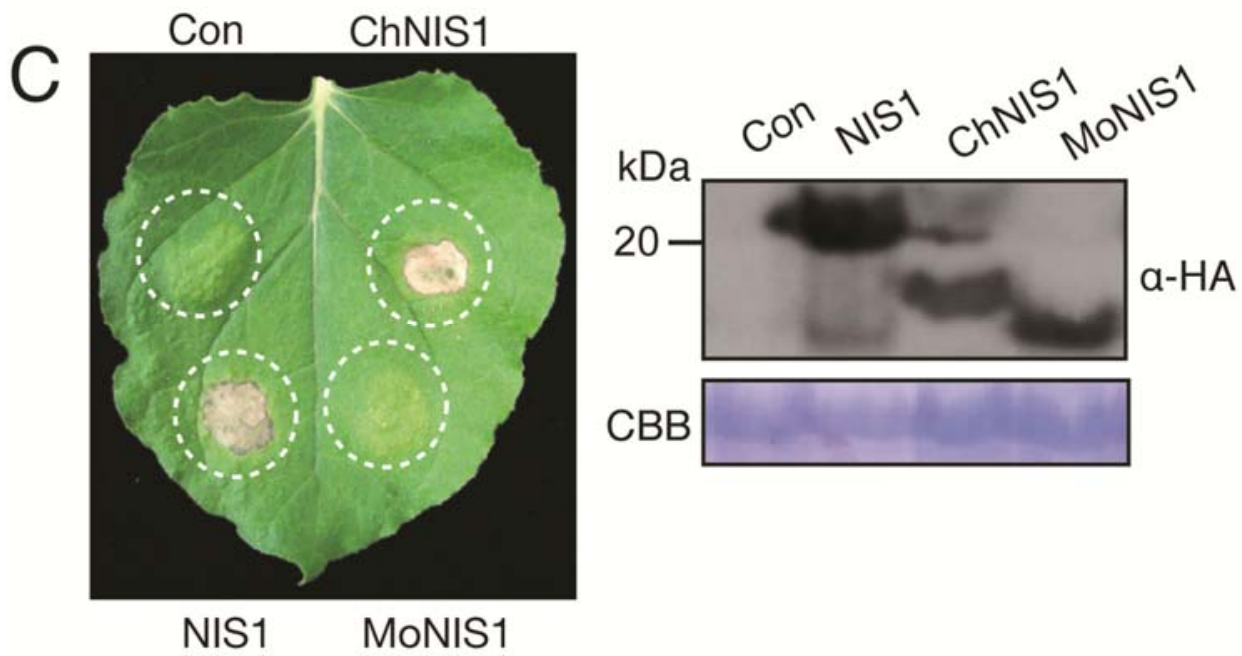

Fig. 5. Regions of necrosis-inducing secreted protein 1 (NIS1) involved in the induction of cell death in Nicotiana benthamiana. A, Agrobacterium tumefaciens cells possessing the empty vector pBICP35 (Con), pBIC-NIS1-HA (NIS1), or pBIC-NIS1 $\Delta$ SP-HA (NIS1 $1 \Delta$ SP) were infiltrated into N. benthamiana (left). Dotted circles indicate the infiltrated regions. The photograph was taken at 7 days postinoculation (dpi). Western blot analysis confirmed the accumulation of NIS and NIS1 $\triangle$ SP (right). Total protein extracted from infiltrated leaves (at $36 \mathrm{~h}$ postinoculation [hpi]) was analyzed by sodium dodecyl sulfate polyacrylamide gel electrophoresis (SDS-PAGE) using anti-HA antibody. B, Agroinfiltration assay for the C-terminal deletion constructs of NIS1. A. tumefaciens cells expressing NIS1-HA (NIS1), the NIS1 $\Delta$ 30-amino-acid HA (NIS1 $\Delta$ C30), or the NIS1 $\Delta 60$-amino-acid HA (NIS1 $\Delta$ C60) were infiltrated into $N$. benthamiana (left). The photograph was taken at 7 dpi. Western blot analysis confirmed the accumulation of the NIS1-HA, NIS1 $\Delta$ C30, and NIS1 $\Delta$ C60 proteins (right). Total protein extracted from infiltrated leaves (at $36 \mathrm{hpi}$ ) was analyzed by SDS-PAGE using anti-HA antibody. C, A. tumefaciens cells expressing NIS1-HA (NIS1), the Colletotrichum higginsianum NIS1 homologue with HA (ChNIS1), or the Magnaporthe oryzae NIS1 homologue with HA (MoNIS1) were infiltrated into $N$. benthamiana (left). The photograph was taken at $7 \mathrm{dpi}$. Western blot analysis using anti-HA antibody confirmed the accumulation of each protein (right). 
and HA-tagged CoDN3 lacking the signal peptide $(\mathrm{CoDN} 3 \Delta \mathrm{SP})$ with a CaMV $35 \mathrm{~S}$ promoter. We infiltrated Agrobacterium tumefaciens strains carrying pBICP35-CoDN3-HA, pBICP35CoDN3 $\triangle \mathrm{SP}-\mathrm{HA}$, or pBICP35 (vector control) in $N$. benthamiana to express the candidate suppressor. After 1 day, infiltration sites were reinfiltrated by A. tumefaciens strains carrying

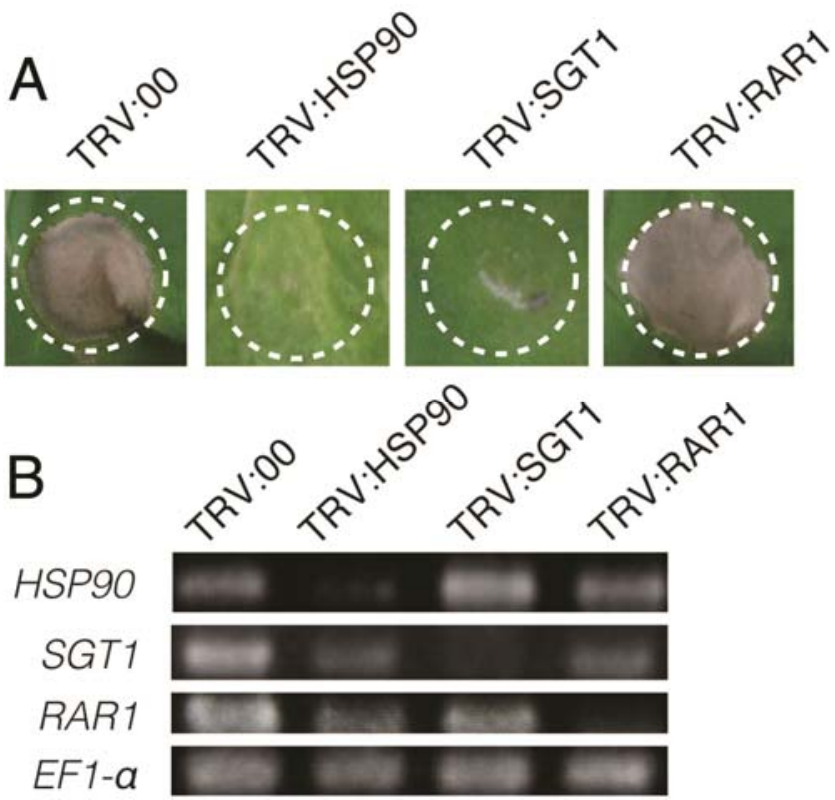

Fig. 6. Necrosis-inducing secreted protein 1 (NIS1)-induced cell death depends on SGT1 and HSP90. A, Nicotiana benthamiana leaves were inoculated for virus-induced gene silencing with TRV:HSP90, TRV:SGT1, and TRV:RAR1. As a control, $N$. benthamiana was inoculated with TRV:00. Agrobacterium tumefaciens cells harboring the pBIC-NIS1-HA were infiltrated into the silenced $N$. benthamiana leaves. Dotted circles indicate the infiltrated regions. Photographs were taken at 7 days postinoculation. The experiment was repeated three times with similar results. B, Semiquantitative reverse-transcription polymerase chain reaction analysis was used to confirm the suppression of $H S P 90, S G T 1$, and RARl in each silenced $N$. benthamiana. EF1- $\alpha$ was used as the control.

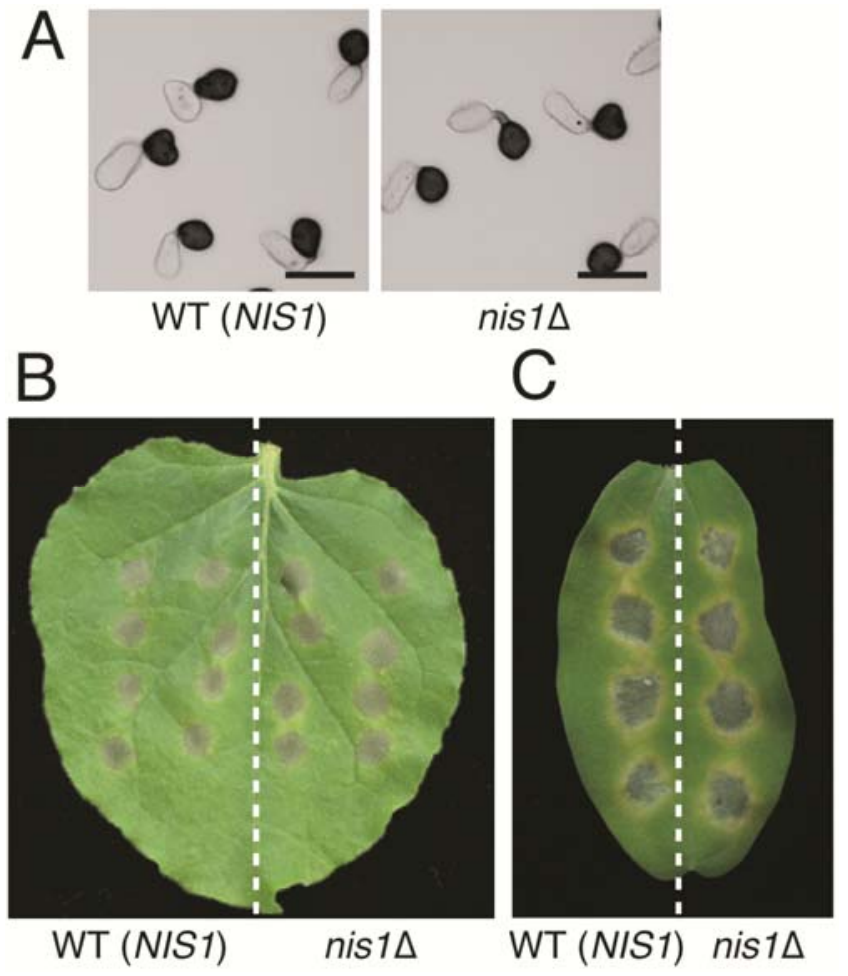

Fig. 7. Pathogenicity assay of the nis $1 \Delta$ mutant on Nicotiana benthamiana and cucumber. A, Appressorium formation of the nis $1 \Delta$ mutant. A conidial suspension of each strain was incubated on glass for $24 \mathrm{~h}$. A, appressorium; $\mathbf{C}$, conidium. Bars $=10 \mu \mathrm{m}$. B, Inoculation assay on $N$. benthamiana . Conidial suspensions $\left(5 \times 10^{5}\right.$ conidia/ml) of tested strains were drop inoculated onto a detached $N$. benthamiana leaf. On the left half, the wildtype strain of Colletotrichum orbiculare was inoculated as a positive control. The nis $1 \Delta$ mutant was inoculated onto the right half. The inoculated leaf was incubated for 7 days. The experiment was repeated three times with similar results. C, Inoculation assay on cucumber. Conidial suspensions $\left(5 \times 10^{5} \mathrm{conidia} / \mathrm{ml}\right)$ of tested strains were drop inoculated onto detached cucumber cotyledon. The inoculated cotyledon was incubated for 7 days. The experiment was repeated three times with similar results.
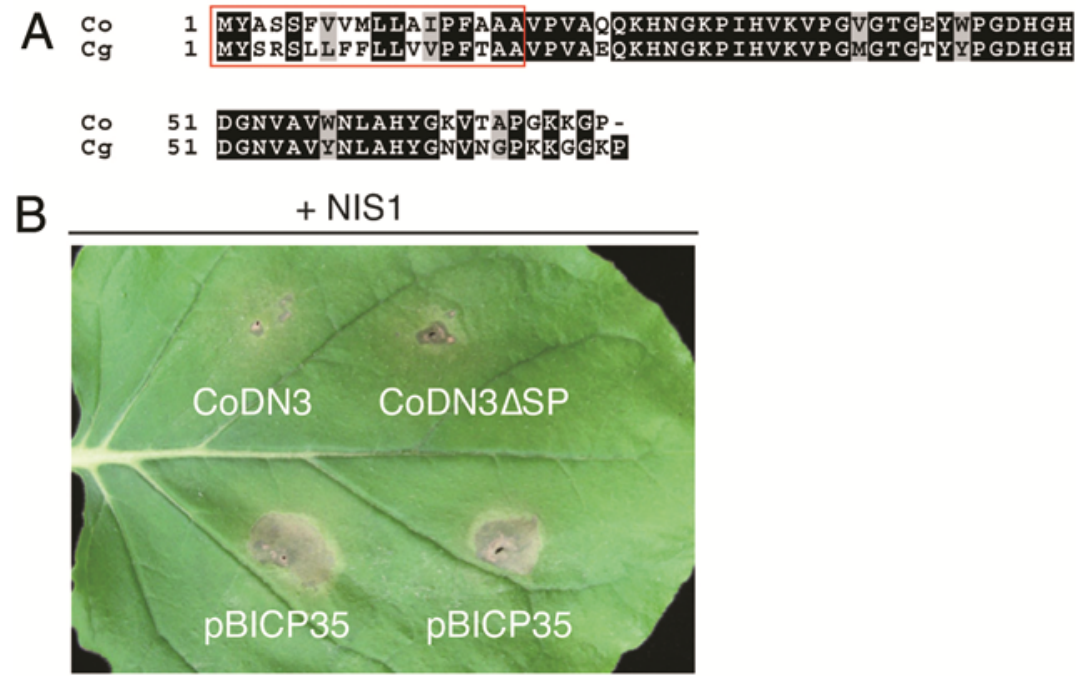

Fig. 8. Suppression of necrosis-inducing secreted protein 1(NIS1)-induced cell death (NCD) by the CgDN3 homologue of Colletotrichum orbiculare. A, Amino acid sequence alignment of $C$. orbiculare $\mathrm{CoDN} 3$ with $\mathrm{CgDN} 3$ of $C$. gloeosporioides. Amino acid sequences were aligned using the Clustal W program (Thompson et al. 1994). Identical amino acids are indicated as white letters on black ground, similar residues are indicated on gray background, and gaps introduced for alignments are indicated by hyphens. The putative signal peptide sequence is indicated by a red open box. B, CoDN3 can suppress NCD in an agroinfiltration assay. Agroinfiltration sites expressing either CoDN3 with HA (CoDN3), CoDN3 $\Delta \mathrm{SP}$ with HA (CoDN3 $\Delta \mathrm{SP})$ or vector control (pBICP35) were challenged with Agrobacterium tumefaciens expressing NIS1 in $N$. benthamiana. NCD was observed in infiltration sites expressing pBICP35 but was suppressed in the CoDN3 or CoDN3 $\Delta$ SP sites. The photograph was taken at 7 days after the challenged infiltration. The experiment was repeated three times with similar results. 
pBIC-NIS1-HA to induce NCD. Notably, we found that CoDN3 suppressed NCD, whereas NCD occurred in case of the preinfiltration of Agrobacterium spp. carrying the vector control (Fig. 8B). CoDN3 $\triangle$ SP also suppressed NCD (Fig. 8B), suggesting that $\mathrm{CoDN} 3$ is a cytoplasmic effector with the suppression activity of NCD.

AVR3a of $P$. infestans is an effector that suppresses cell death triggered by the elicitin protein INF1 (Bos et al. 2006). Detailed analysis of AVR3a, including structure analysis of its homologue AVR3a4, revealed that AVR3a targets and stabilizes the ubiquitin E3-ligase CMPG1 of $N$. benthamiana with its phosphatidylinositol monophosphate-binding ability of the AVR3a effector domain (Bos et al. 2006, 2009; Yaeno et al. 2011). We investigated whether Avr3a (AVR3a $\left.{ }^{\mathrm{KI}} \Delta 23-147\right)$ can suppress NCD or not by the Agrobacterium spp.-mediated suppression assay described above. As a result, AVR3a suppressed cell death induced by INF1 but not NCD (Fig. 9), suggesting that CPMG1 is not involved in NCD. CoDN3 also failed to suppress the INF1-induced cell death (Fig. 9).

\section{DISCUSSION}

We identified a novel secreted protein gene, NIS1, of C. orbiculare by functional screening of $C$. orbiculare cDNAs in a virus vector-based in planta expression system. We showed that transient expression of NIS1 caused cell death in $N$. benthamiana in an SGT1- and HSP90-dependent manner. Culture filtrates of $C$. orbiculare induced cell death in $N$. benthamiana, which depends on NIS1. Microscopic analysis of $C$. orbiculare transgenic strains carrying the NIS1 promoter (NIS1p) fused to GFP revealed that NIS1 is preferentially expressed during the biotrophic stage of $C$. orbiculare. These data strongly suggest that $C$. orbiculare expresses secreted protein NIS1 during plant infection, which can trigger NCD in N. benthamiana.

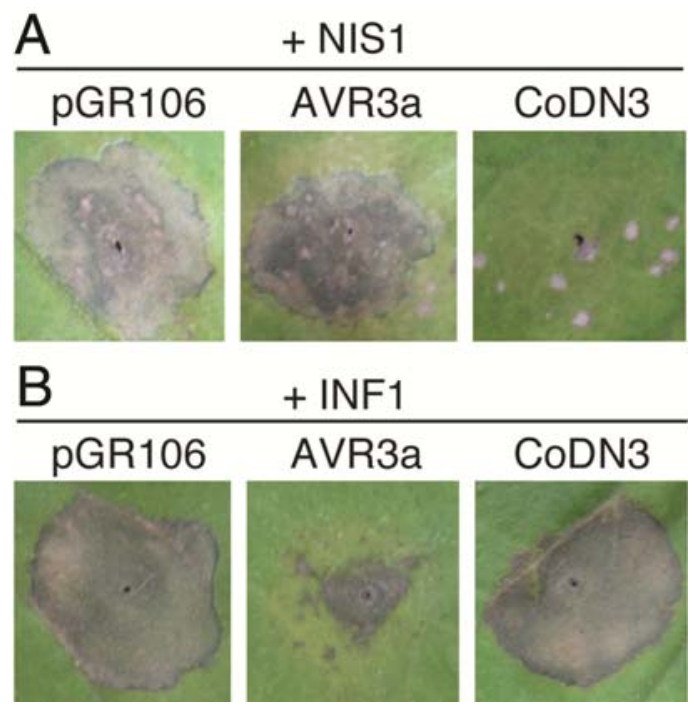

Fig. 9. Difference in cell death suppression between CoDN3 and AVR3a. A, Agroinfiltration sites expressing either vector control (pGR106), AVR3a ${ }^{\mathrm{KI}} \Delta 23-147$ (AVR3a), or CoDN3 with HA (CoDN3) were challenged with Agrobacterium tumefaciens expressing necrosis-inducing secreted protein 1 (NIS1) in $N$. benthamiana. NIS1-induced cell death was observed in infiltration sites expressing pGR106 or AVR3a but was suppressed in the CoDN3 sites. Photographs were taken at 11 days after the challenged infiltration. The experiment was repeated three times with similar results. B, Agroinfiltration sites expressing either pGR106, AVR3a, or CoDN3 were challenged with A. tumefaciens expressing INF1 in $N$. benthamiana. The INF1-induced cell death was observed in infiltration sites expressing pGR106 or CoDN3 but was strongly reduced in the AVR3a sites. Photographs were taken at 8 days after the challenged infiltration. The experiment was repeated three times with similar results.
NIS1 homologues are found in a part of fungi belonging to Sordariomycetes, Dothideomycetes, or Orbiliomycetes. Although the putative NIS1 homologues of $C$. higginsianum and C. graminicola exhibit high similarity to NIS1, NIS1 homologues in the other fungi show low similarity to NIS1 (Fig. 2). Furthermore, we did not find the NIS1 homologues in the genome sequence of plant pathogens $V$. albo-atrum belonging to Sordariomycetes and L. maculans belonging to Dothideomycetes. Therefore, we speculate that NIS1 originated from an ancestral fungus of Sordariomycetes, Dothideomycetes, and probably Orbiliomycetes, and that NISI homologues might have been changed or deleted, possibly through host-pathogen co-evolution.

PAMPs are usually considered to be invariant or highly constrained structures that are extremely difficult for microbes to alter because of fitness penalties. Because elicitins, including INF1, fulfill a number of the criteria ascribed to PAMPs (Jiang et al. 2006; Vleeshouwers et al. 2006), elicitins are currently regarded as possible PAMP-related proteins. NIS1 is conserved in a part of fungi belonging to Sordariomycetes, Dothideomycetes, or Orbiliomycetes, implying that NIS1 has a property of PAMPs. However, the sequences homologous to NIS1 are likely absent in multiple plant-pathogenic fungi belonging to Sordariomycetes or Dothideomycetes, and the sequence diversity among the putative NIS 1 homologues is also relatively high. Also, the homologue of $M$. oryzae did not induce cell death in $N$. benthamiana (Fig. 5C). Furthermore, the deletion of NISI had no detectable effects on pathogenicity of $C$. orbiculare on both cucumber and $N$. benthamiana, suggesting that NIS1 does not meet the criteria for typical PAMPs. Therefore, we currently consider that NIS1 is an evolutionarily ancient and well-conserved effector rather than a PAMP-related protein, although we are now realizing the ambiguous dichotomy between PAMP and effector (Thomma et al. 2011). The finding that the nis $1 \Delta$ mutants showed virulence on cucumber at the WT level indicated that NIS1 is dispensable for virulence of $C$. orbiculare, possibly because of the functional redundancy with other effectors. Also, we now speculate that NCD depends on recognition of NIS1 via a corresponding plant receptor but there is also a possibility that NIS1 has some phytotoxic activity like the NLP effectors, although NIS1 has no sequence similarity with NLP.

The NIS1 product expressed in N. benthamiana was detected as a band with a higher weight than the predicted molecular weight. In contrast, NIS $1 \Delta$ SP also showed a size similar to the predicted molecular size, suggesting that NIS1 has a modification during its secretion process (Fig. 5A). Because the majority of secreted proteins are glycosylated in living organisms, the data suggest that NIS1 is glycosylated in the endoplasmic reticulum and the Golgi apparatus during the secretion process. Interestingly, the NIS1 protein expressed in fungal cells was larger than NIS1 expressed in $N$. benthamiana (Figs. 3A and $5 \mathrm{~A})$, suggesting that the presumed glycosylation patterns of NIS1 seem to differ between $N$. benthamiana and $C$. orbiculare. In contrast to the full-length NIS1, both NIS1 $\Delta \mathrm{C} 30$ and NIS1 $\Delta$ C60 expressed in $N$. benthamiana were detected as bands that matched the predicted molecular weight (Fig. 5B), suggesting that the carboxyl 30 -amino-acid region of NIS 1 is likely glycosylated. Consistently, the NetNGlyc1.0 server predicted a potential $\mathrm{N}$-glycosylation site of NIS1 at the position 150 Asn that is located in the 30-amino-acid carboxyl region (Fig. 2C). ChNIS1 induced cell death in N. benthamiana, and the ChNIS1 product was detected as a band that matched its predicted molecular weight (Fig. 5C). This suggests that ChNIS1 is not glycosylated in N. benthamiana, which is also supported by the absence of the position 150 Asn in ChNIS1 
(Fig. 2C). Therefore, we consider that modification of C. orbiculare NIS1 is likely not essential for NCD. The NIS1 secreted in culture filtrate was detected as a band with a higher weight than a band corresponding to NIS1 detected inside fungal cells (Fig. 3A), implying a possibility that NIS1 present in culture filtrate formed a oligomerized complex resistant to sodium dodecyl sulfate (SDS).

A VIGS assay showed that SGT1 and HSP90 are required for NCD but RAR1 is not required. SGT1 and RAR1 both interact with HSP90, probably as co-chaperones (Shirasu 2009; Zhang et al. 2010), and the HSP90-SGT1-RAR1 complex recruits nucleotide-binding leucine-rich repeat receptors encoded by $R$ genes. Consistent with this, RAR1 and SGT1 are required for the many resistance pathways conferred by $R$ genes (Shirasu and Schulze-Lefert 2003). However, the roles of the RAR1 and SGT1 genes are not universal and these genes are not essential for resistance involving some $R$ genes (Shirasu and Schulze-Lefert 2003). The HSP90-SGT1 complex without RAR1 might be sufficient for the functioning of a putative NIS1 receptor of $N$. benthamiana. However, both SGT1 and HSP90 are also required for cell death induced by INF 1 and an NLP gene of $P$. infestans (PiNPP1.1) (Kanneganti et al. 2006; Kanzaki et al. 2003; Peart et al. 2002); thus, the requirement of NCD for SGT1 and HSP90 does not necessarily suggest that NIS1 is recognized as an AVR effector.

The deletion of the NIS1 gene had no clear impact on C. orbiculare infection of $N$. benthamiana, whereas the cell-deathinducing activity of the culture filtrate was severely reduced in the nis $1 \Delta$ mutant compared with the WT. This finding suggested that NIS1 is expressed at the infectious phase but the effect of NIS1 might be suppressed by an unidentified effector or effectors. We identified the homologue of the $C g D N 3$ gene, named CoDN3, from $C$. orbiculare and showed that CoDN3 can suppress NCD in the Agrobacterium sp.-mediated suppression assay. The homology search of the $D N 3$ genes against fungal genome sequences suggests that the $D N 3$ genes are only present in Colletotrichum spp. (C. gloeosporioides, C. orbiculare, and $C$. higginsianum), whereas the DN3 gene is unlikely present in the maize anthracnose pathogen $C$. graminicola.

The $C g D N 3$ knockout mutants of $C$. gloeosporioides increased elicitation of a localized HR-like response and, importantly, the mutants failed to infect its host plant, indicating the requirement of $\mathrm{CgDN3}$ in the virulence of $C$. gloeosporioides (Stephenson et al. 2000). Together with our finding that CoDN3 can suppress NCD, we speculate that NCD likely accompanies defense response that has inhibitory effects on pathogenic invasive growth of $C$. orbiculare inside $N$. benthamiana. To know the detailed function of $C o D N 3$ in $C$. orbiculare, it is necessary to perform targeted gene disruption analysis of CoDN3 and investigate the mutant phenotypes in future.

We showed here that CoDN3 failed to suppress the INF1induced cell death. Thus, the cell-death pathway triggered by NIS1 is likely distinct from that triggered by INF1, although NCD and INF1-induced cell death share SGT1 and HSP90. The RXLR effector Avr $3 \mathrm{a}^{\mathrm{KI}}$ of $P$. infestans targets a host ubiquitin E3-ligase CMPG1. We found that Avr3a ${ }^{\mathrm{KI}}$ failed to suppress NCD, suggesting that CMPG1 is not involved in NCD. CoDN3 lacking its signal peptide retained the ability to suppress NCD, strongly suggesting that $\mathrm{CoDN} 3$ is a cytoplasmic effector of $C$. orbiculare. It is assumed that the secreted CoDN3 protein is translocated into the host cytoplasm and targets a cytoplasmic plant component required for NCD. For further understanding of the NCD pathway and the CoDN3 function at a molecular level, it is important to identify the targets of the effector CoDN3 in $N$. benthamiana. The use of $N$. benthamiana has advantages for this purpose (i.e., in this plant, transient overexpression of the tagged effectors enables an effective co-immunoprecipitation assay of the effector-target protein complex) (Win et al. 2011).

\section{MATERIALS AND METHODS}

Fungal strains, media, transformation, and DNA analysis.

The $C$. orbiculare (syn. C. lagenarium) WT strain 104-T (MAFF240422) was a stock culture of the Laboratory of Plant Pathology, Kyoto University. M. oryzae 70-15 and C. higginsianum MAFF305635 were used for cloning of the putative NIS1 homologues. Cultures of the all fungal isolates were maintained on $3.9 \%(\mathrm{wt} / \mathrm{vol})$ potato dextrose agar medium (Difco, Detroit) at $24^{\circ} \mathrm{C}$ in the dark. The transformation of $C$. orbiculare has been described previously (Kimura et al. 2001). Restriction enzyme digestion, cloning, plasmid isolation, and gel electrophoresis were performed according to the manufacturers' instructions and standard methods (Sambrook et al. 1989).

\section{Construction of $C$. orbiculare cDNA library and functional screening in $N$. benthamiana.}

To synthesize cDNA of $C$. orbiculare, total RNA of $C$. orbiculare was isolated from i) conidia incubated on glass for 3 , 6 , or $9 \mathrm{~h}$ (approximately $10^{6}$ conidia/ml) and ii) $N$. benthamiana leaves where $C$. orbiculare conidia were inoculated (incubated for 24, 36, 72, and $96 \mathrm{~h}$ ) using the RNeasy plant mini kit (Qiagen, Hilden, Germany) according to the manufacturer's instructions.

cDNA of $C$. orbiculare was synthesized from isolated RNA using the SMART cDNA Library Construction Kit (Clontech, Mountain View, CA, U.S.A.) according to the manufacturer's instructions. The cDNA was directionally ligated into a binary PVX-based vector (pSfinx) (Takken et al. 2000). The ligation mixture was transformed to electrocompetent cells of A. tumefaciens by electrotransformation using Gene Pulser II (BioRad, Hercules, CA, U.S.A.). A. tumefaciens GV3101, containing the pSoup, was used for the transformation. Electroporated cells were diluted with $1 \mathrm{ml}$ of tryptone at $20 \mathrm{~g} / \mathrm{liter}$, yeast extract at $5 \mathrm{~g} /$ liter, $\mathrm{NaCl}$ at $0.58 \mathrm{~g} /$ liter, $\mathrm{KCl}$ at $0.2 \mathrm{~g} /$ liter, glucose at $3.6 \mathrm{~g} /$ liter, $0.01 \mathrm{M} \mathrm{MgSO}_{4}$, and $0.01 \mathrm{M} \mathrm{MgCl}_{2}$ and incubated at $28^{\circ} \mathrm{C}$ for $3 \mathrm{~h}$. Subsequently, this solution was plated on $\mathrm{Lu}-$ ria-Bertani (LB) agar supplemented with kanamycin at 100 $\mu \mathrm{g} / \mathrm{ml}$, rifampicin at $100 \mu \mathrm{g} / \mathrm{ml}$, and tetracycline at $5 \mu \mathrm{g} / \mathrm{ml}$. For functional cDNA screening in $N$. benthamiana, colonies of A. tumefaciens transformants were toothpick inoculated on intact $N$. benthamiana leaves. From 10 days after inoculation, leaves were examined for the presence of necrosis around the inoculation sites.

\section{Plasmid constructs.}

To generate the NIS1 replacement vector pGDNIS1, the 3.7$\mathrm{kb}$ fragment containing the 3' flanking region of NIS1 was amplified using PCR and primers NIS1ko3fwd and NIS1ko3rev. The NIS1ko3fwd primer contains an XhoI site and the NIS1ko3rev primer contains an ApaI site. The amplified product was digested with $X h o \mathrm{I}$ and $A p a \mathrm{I}$ and introduced into the XhoI-ApaI site of pCB1636 (Sweigard et al. 1997) containing a hygromycin-resistant gene to produce plasmid pGD3NIS1. The 4-kb fragment of the 5' flanking region of NIS1 was amplified using PCR and the primers NIS1ko5fwd and NIS1ko5rev. The NIS1ko5fwd primer contains a NotI site and the NIS1ko5rev primer contains a BamHI site. The amplified product was digested with $\operatorname{NotI}$ and BamHI and introduced into the NotI-BamHI site of pGD3NIS1 to produce pGDNIS1.

CoDN3 was found by searching against partial genome sequences of $C$. orbiculare obtained from sequencing genomic clones of the cosmid library. The cDNA sequences of $C$. orbiculare NIS1 (GenBank accession number AB669517), MoNIS1 
(XP_365645), ChNIS1 (CH063_03697 in Colletotrichum Database), and CoDN3 (AB686523) were amplified from a cDNA pool of each fungus using PCR and primer sets 35SpNIS1fwd and 35SpNIS1rev, 35SpMoNIS1fwd and 35SpMoNIS1rev, 35SpChNIS1fwd and 35SpChNIS1rev, CoDN3-BamHI-f and CoDN3-HA-EcoRI-r(c), respectively. Each rev primer contained an HA-tag sequence. Each amplified product was digested with BamHI and EcoRI and introduced into the BamHI-EcoRI site of pBICP35 (Mori et al. 1991), which resulted in 35S-NIS1-HA, 35S-MoNIS1-HA, 35S-ChNIS1-HA, and 35S-CoDN3-HA, respectively. To generate the reporter construct NIS1p-GFP, the $1.5-\mathrm{kb} 5^{\prime}$ upstream region of NIS1 was amplified using PCR and primers NIS1pGFPfwd and NIS1pGFPrev. The NIS1pGFPfwd primer contains an NotI site and the NIS1pGFPrev primer contains an $\mathrm{XbaI}$ site. The amplified product was digested with NotI and $X b a \mathrm{I}$ and introduced into the NotI-XbaI site of pBAFPGFP (Kojima et al. 2004).

To express the HA-tagged NIS 1 under the TEF promoter, we generated pCB16NIS1TEFP. The 242-bp downstream region of SCDI was introduced into the HindIII-ClaI site of pCB16EGFP (Kimura et al. 2001; Takano et al. 2001), resulting in pCB16GFPST, and the 221-bp upstream region of SCD1 was introduced into the NotI site of pCB16GFPST (Takano et al. 2001), resulting in pCB16GFPSTSP. The TEF promoter was digested with NotI and $X b a \mathrm{I}$ from pBATTEFPMR (Asakura et al. 2009) and introduced into the Not I-XbaI site of pCB16GFPSTSP, resulting in pCB16TEFP. The NIS1 fragment was amplified using PCR and primers TEFpNIS1fwd and TEFpNIS1rev. The amplified product was digested with $X b a \mathrm{I}$ and BamHI and introduced into the XbaI-BamHI site of pCB16TEFP, which resulted in pCB16NIS1TEFP.

To express NIS1 and CoDN3 deletions tagged with HA at the C-terminus under the $35 \mathrm{~S}$ promoter, sequences encoding NIS1HA lacking its signal peptide (NIS1 $\Delta$ SP), CoDN3-HA lacking its signal peptide (DN3 $\Delta$ SP), NIS1-HA lacking $30 \mathrm{C}$-terminal amino acids (NIS1 $\Delta \mathrm{C} 30$ ), and NIS1-HA lacking $60 \mathrm{C}$-terminal amino acids (NIS1 $\Delta$ C60) were amplified using PCR and primer sets 35SpNIS1dSPfwd and 35SpNIS1rev, CoDN3dSP-BamHI-f and CoDN3-HA-EcoRI-r(c), 35SpNIS1fwd and 35SpNIS1d30rev, and 35SpNIS1fwd and 35SpNIS1d60rev, respectively. Each amplified product was digested with BamHI and EcoRI and introduced into the BamHI-EcoRI site of pBICP35. Supplementary Table S1 shows a list of primers used in plasmid constructions.

\section{Plant lines, growth, and inoculation.}

$N$. benthamiana and cucumber (Cucumis sativus) were grown on soil at $25^{\circ} \mathrm{C}$ with $16 \mathrm{~h}$ of illumination per day. Inoculation of Colletotrichum orbiculare on $N$. benthamiana and cucumber was performed as described previously (Takano et al. 2006).

\section{Fluorescence microscopy.}

To assess GFP signaling in reporter strains of $C$. orbiculare, conidia of the reporter strains were incubated on multiwell glass microscope slides (MP Biomedicals, Costa Mesa, CA, U.S.A.) or inoculated on the lower surfaces of cucumber cotyledons at $25^{\circ} \mathrm{C}$. Detection of GFP fluorescence was performed using an Olympus Fluoview FV500 confocal microscope with a Nikon 60× PlanApo (1.4 numerical aperture) oil-immersion objective. Samples were mounted in water under cover slips using an argon laser. We used diachronic mirror DM488/543, an SDM560 beam splitter, and emission filter BA505-525.

\section{VIGS.}

VIGS was done as described by Ratcliff and associates (2001). N. benthamiana was infected by viruses via agroinfiltration of infectious constructs. pBINTRA6 (RNA1) and pTV00 containing the inserts (RNA2) were transformed separately by electroporation into Agrobacterium sp. strain GV3101. A mixture of equal parts of Agrobacterium spp. suspensions of RNA1 and RNA2 was inoculated into 2- to 3-week-old N. benthamiana seedlings. The upper leaves of the inoculated plants were used for assays 3 to 4 weeks after inoculation. The effect of VIGS was confirmed by reverse-transcription (RT)-PCR. An Agrobacterium sp. carrying pBIC-NIS1-HA was infiltrated into $N$. benthamiana leaves. At $7 \mathrm{dpi}$, the noninfiltrated regions of the leaves were excised and total RNA was extracted from them using the Qiagen RNeasy Plant Mini Kit. Extracted total RNA was treated with DNase (Promega RQ1 RNase-free DNase, Charbonnières, France) to remove DNA contamination. The Takara PrimeScript RT reagent kit (Takara Bio, Shiga, Japan) was used to obtain cDNA.

\section{Western blot analysis.}

Samples were ground in liquid nitrogen and incubated in denaturing buffer (62.5 mM Tris- $\mathrm{HCl}$ [pH 6.8], 1\% SDS, and $1 \%$ 2-mercaptoethanol) for $5 \mathrm{~min}$ at $95^{\circ} \mathrm{C}$. Western blot analysis was performed essentially as previously described (Takeda et al. 2005). Sample proteins were analyzed by polyacrylamide gel electrophoresis using gels containing $15 \%$ polyacrylamide and $0.1 \%$ SDS and transferred to polyvinylidene difluoride membranes (Immobilon-P; Millipore, Bedford, MA, U.S.A.). Anti-HA monoclonal antibody (3F10; Roche, Mannheim, Germany) was used as the primary antibody. Alkaline phosphatase-conjugated anti-rabbit immuonoglobulin $\mathrm{G}$ antibody (Cell Signaling Technology, Beverley, MA, U.S.A.) was used as secondary antibody. The signals were visualized with CDP-star (Roche) and detected using a luminescent-image analyzer (LAS 1000 Plus; Fujifilm, Tokyo). For Western blot analysis of culture filtrates, we used the acetone precipitation method to concentrate the culture filtrate of $C$. orbiculare. The culture filtrate was dissolved in cold acetone (twice the sample volume) and incubated for $2 \mathrm{~h}$ at $-20^{\circ} \mathrm{C}$. After incubation, the mixture was centrifuged for 15 min and supernatant was discarded. The protein pellet was then suspended in distilled water.

\section{Culture filtrate preparation and infiltration.}

To prepare the culture filtrate for analysis, $C$. orbiculare was incubated in liquid complete medium (CM) at $140 \mathrm{rpm}$ for 48 $\mathrm{h}$ at $24^{\circ} \mathrm{C}$. $\mathrm{CM}$ contains $6.0 \mathrm{~g}$ of $\mathrm{NaNO}_{3}, 0.5 \mathrm{~g}$ of $\mathrm{MgSO}_{4}$. $7 \mathrm{H}_{2} \mathrm{O}, 0.5 \mathrm{~g}$ of KCl, $1.5 \mathrm{~g}$ of $\mathrm{KH}_{2} \mathrm{PO}_{4}, 0.001 \%$ thiamine, $0.1 \%$ trace elements, $10 \mathrm{~g}$ of glucose, $1.0 \mathrm{~g}$ of casamino acids, $2.0 \mathrm{~g}$ of peptone, and $1.0 \mathrm{~g}$ of yeast extract per liter $(\mathrm{pH} \mathrm{6.5)}$. Vegetative mycelia were removed using the gauze and $0.22 \mu \mathrm{m}$ Millex-GS (Millipore). The protein concentration of the culture filtrate was adjusted to $5 \mu \mathrm{g} / \mathrm{ml}$ using a Coomassie (Bradford) protein assay kit (Pierce, Rockford, IL, U.S.A.), infiltrated into $N$. benthamiana leaves using a syringe, and incubated for 9 days at $25^{\circ} \mathrm{C}$.

\section{A. tumefaciens-mediated transient expression in $N$. benthamiana.}

$N$. benthamiana plants (5 to 6 weeks old) were used for the agroinfection assays. Plants were grown in a controlled environment chamber at $25^{\circ} \mathrm{C}$ with $16 \mathrm{~h}$ of illumination per day. Each construct (pBICP35, pBIC-NIS1-HA, pBIC-NIS1 $\triangle$ SPHA, pBIC-NIS1-30-HA, pBIC-NIS1-60-HA, pBIC-MoNIS1HA, pBIC-ChNIS1-HA, pBICP35-CoDN3-HA, pBICP35CoDN3 $\Delta$ SP-HA, pGR106, pGR106-AVR $3{ }^{\mathrm{KI}} \Delta 23-147$, and p35S-INF1) was transformed into Agrobacterium sp. strain GV3101 by electroporation. Each transformant was cultured in LB containing kanamycin $(100 \mu \mathrm{g} / \mathrm{ml})$, rifampicin (100 $\mu \mathrm{g} / \mathrm{ml})$, and gentamicin $(50 \mu \mathrm{g} / \mathrm{ml})$. The cells were harvested by centrifugation and were resuspended in $10 \mathrm{mM}$ morpholine- 
ethanesulfonic acid (MES)-NaOH (pH 5.6), $10 \mathrm{mM} \mathrm{MgCl}_{2}$, and $150 \mu \mathrm{M}$ acetosyringone. The suspensions were infiltrated into $N$. benthamiana leaves using a syringe. Similar procedures were used for the suppression assays, except that the cells were suspended in MMA induction buffer (1 liter of MMA contained $5 \mathrm{~g}$ of Murashige-Skoog salts, $1.95 \mathrm{~g}$ of MES, $20 \mathrm{~g}$ of sucrose, and $200 \mu \mathrm{M}$ acetosyringone, $\mathrm{pH}$ 5.6). In the suppression assay, at 1 day after infiltration, the infiltration sites were challenged with recombinant $A$. tumefaciens carrying pBIC-NIS1-HA or p35S-INF1. All suspensions were incubated for $1 \mathrm{~h}$ prior to infiltration. NIS1-induced lesions were observed at 5 to 8 days after the infiltration whereas INF1induced lesions were observed at 3 to 5 days.

\section{ACKNOWLEDGMENTS}

We thank D. Baulcombe for the pTV00 vector; J. Andrews for pTEFEGFP; R. Dean for M. oryzae; M. Joosten for pSfinx; S. Kamoun for pGR106, pGR106-AVR3 ${ }^{\mathrm{KI}}(\Delta 23-147)$, and p35S-INF1; and K. Ikeda for technical assistance. This work was supported by a Grant-in-Aid for Scientific Research (number 20380027) from the Ministry of Education, Culture, Sports, Science and Technology (MEXT) of Japan and by the Program for Promotion of Basic Research Activities for Innovative Biosciences.

\section{LITERATURE CITED}

Asakura, M., Ninomiya, S., Sugimoto, M., Oku, M., Yamashita, S., Okuno, T., Sakai, Y., and Takano, Y. 2009. Atg26-mediated pexophagy is required for host invasion by the plant pathogenic fungus Colletotrichum orbiculare. Plant Cell 21:1291-1304.

Bailey, J. A., and Jeger, M. J. 1992. Colletotrichum: Biology, Pathology and Control. CAB International, Wallingford, U.K.

Bhadauria, V., Banniza, S., Vandenberg, A., Selvaraj, G., and Wei, Y. 2011. EST mining identifies proteins putatively secreted by the anthracnose pathogen Colletotrichum truncatum. BMC Genomics 12:327.

Boller, T., and Felix, G. 2009. A renaissance of elicitors: Perception of microbe-associated molecular patterns and danger signals by patternrecognition receptors. Annu. Rev. Plant Biol. 60:379-406.

Bos, J. I., Kanneganti, T. D., Young, C., Cakir, C., Huitema, E., Win, J., Armstrong, M. R., Birch, P. R., and Kamoun, S. 2006. The C-terminal half of Phytophthora infestans RXLR effector AVR3a is sufficient to trigger R3a-mediated hypersensitivity and suppress INF1-induced cell death in Nicotiana benthamiana. Plant J. 48:165-176.

Bos, J. I., Chaparro-Garcia, A., Quesada-Ocampo, L. M., McSpadden Gardener, B. B., and Kamoun, S. 2009. Distinct amino acids of the Phytophthora infestans effector AVR3a condition activation of R3a hypersensitivity and suppression of cell death. Mol. Plant-Microbe Interact. 22:269-281.

Bos, J. I., Armstrong, M. R., Gilroy, E. M., Boevink, P. C., Hein, I., Taylor, R. M., Zhendong, T., Engelhardt, S., Vetukuri, R. R., Harrower, B., Dixelius, C., Bryan, G., Sadanandom, A., Whisson, S. C., Kamoun, S., and Birch, P. R. 2010. Phytophthora infestans effector AVR3a is essential for virulence and manipulates plant immunity by stabilizing host E3 ligase CMPG1. Proc. Natl. Acad. Sci. U.S.A. 107:9909-9914.

Chisholm, S. T., Coaker, G., Day, B., and Staskawicz, B. J. 2006. Host-microbe interactions: Shaping the evolution of the plant immune response. Cell 124:803-814.

de Jonge, R., Bolton, M. D., and Thomma, B. P. H. J. 2011. How filamentous pathogens co-opt plants: The ins and outs of fungal effectors. Curr. Opin. Plant Biol. 14:400-406.

Gilroy, E. M., Taylor, R. M., Hein, I., Boevink, P., Sadanandom, A., and Birch, P. R. 2011. CMPG1-dependent cell death follows perception of diverse pathogen elicitors at the host plasma membrane and is suppressed by Phytophthora infestans RXLR effector AVR3a. New Phytol. 190:653-666.

Houterman, P. M., Cornelissen, B. J., and Rep, M. 2008. Suppression of plant resistance gene-based immunity by a fungal effector. PLoS Pathog. 4:e1000061. Published online.

Jiang, R. H., Tyler, B. M., Whisson, S. C., Hardham, A. R., and Govers, F. 2006. Ancient origin of elicitin gene clusters in Phytophthora genomes. Mol. Biol. Evol. 23:338-351.

Jones, J. D., and Dangl, J. L. 2006. The plant immune system. Nature 444:323-329.

Kanneganti, T. D., Huitema, E., Cakir, C., and Kamoun, S. 2006. Synergistic interactions of the plant cell death pathways induced by Phytophthora infestans Nepl-like protein PiNPP1.1 and INF1 elicitin. Mol.
Plant-Microbe Interact. 19:854-863.

Kanzaki, H., Saitoh, H., Ito, A., Fujisawa, S., Kamoun, S., Katou, S., Yoshioka, H., and Terauchi, R. 2003. Cytosolic HSP90 and HSP70 are essential components of INF1-mediated hypersensitive response and non-host resistance to Pseudomonas cichorii in Nicotiana benthamiana. Mol. Plant Pathol. 4:383-391.

Kelley, B. S., Lee, S. J., Damasceno, C. M., Chakravarthy, S., Kim, B. D., Martin, G. B., and Rose, J. K. 2010. A secreted effector protein (SNE1) from Phytophthora infestans is a broadly acting suppressor of programmed cell death. Plant J. 62:357-366.

Kimura, A., Takano, Y., Furusawa, I., and Okuno, T. 2001. Peroxisomal metabolic function is required for appressorium-mediated plant infection by Colletotrichum lagenarium. Plant Cell 13:1945-1957.

Kleemann, J., Takahara, H., Stuber, K., and O'Connell, R. 2008. Identification of soluble secreted proteins from appressoria of Colletotrichum higginsianum by analysis of expressed sequence tags. Microbiology 154:1204-1217.

Kojima, K., Takano, Y., Yoshimi, A., Tanaka, C., Kikuchi, T., and Okuno, T. 2004. Fungicide activity through activation of a fungal signalling pathway. Mol. Microbiol. 53:1785-1796.

Krijger, J. J., Horbach, R., Behr, M., Schweizer, P., Deising, H. B., and Wirsel, S. G. 2008. The yeast signal sequence trap identifies secreted proteins of the hemibiotrophic corn pathogen Colletotrichum graminicola. Mol. Plant-Microbe Interact. 21:1325-1336.

Lee, N., D'Souza, C. A., and Kronstad, J. W. 2003. Of smuts, blasts, mildews, and blights: cAMP signaling in phytopathogenic fungi. Annu. Rev. Phytopathol. 41:399-427.

Lu, R., Martin-Hernandez, A. M., Peart, J. R., Malcuit, I., and Baulcombe, D. C. 2003. Virus-induced gene silencing in plants. Methods 30:296303.

Ma, W, Dong, F. F., Stavrinides, J., and Guttman, D. S. 2006. Type III effector diversification via both pathoadaptation and horizontal transfer in response to a coevolutionary arms race. PLoS Genet. 2:e209. Published online.

Miyara, I., Shafran, H., Kramer Haimovich, H., Rollins, J., Sherman, A., and Prusky, D. 2008. Multi-factor regulation of pectate lyase secretion by Colletotrichum gloeosporioides pathogenic on avocado fruits. Mol. Plant Pathol. 9:281-91.

Mori, M., Mise, K., Kobayashi, K., Okuno, T., and Furusawa, I. 1991. Infectivity of plasmids containing brome mosaic virus cDNA linked to the cauliflower mosaic virus 35S RNA promoter. J. Gen. Virol. 72:243-246.

Ottmann, C., Luberacki, B., Kufner, I., Koch, W., Brunner, F., Weyand, M., Mattinen, L., Pirhonen, M., Anderluh, G., Seitz, H. U., Nurnberger, T., and Oecking, C. 2009. A common toxin fold mediates microbial attack and plant defense. Proc. Natl. Acad. Sci. U.S.A. 106:1035910364.

Peart, J. R., Lu, R., Sadanandom, A., Malcuit, I., Moffett, P., Brice, D. C., Schauser, L., Jaggard, D. A., Xiao, S., Coleman, M. J., Dow, M., Jones, J. D., Shirasu, K., and Baulcombe, D. C. 2002. Ubiquitin ligase-associated protein SGT1 is required for host and nonhost disease resistance in plants. Proc. Natl. Acad. Sci. U.S.A. 99:10865-10869.

Pemberton, C. L., and Salmond, G. P. 2004. The Nep1-like proteins-a growing family of microbial elicitors of plant necrosis. Mol. Plant Pathol. 5:353-359.

Perfect, S. E., Hughes, H. B., O'Connell, R. J., and Green, J. R. 1999. Colletotrichum: A model genus for studies on pathology and fungal-plant interactions. Fungal Genet. Biol. 27:186-198.

Ratcliff, F., Martin-Hernandez, A. M., and Baulcombe, D. C. 2001. Technical advance. Tobacco rattle virus as a vector for analysis of gene function by silencing. Plant J. 25:237-245.

Rosebrock, T. R., Zeng, L., Brady, J. J., Abramovitch, R. B., Xiao, F., and Martin, G. B. 2007. A bacterial E3 ubiquitin ligase targets a host protein kinase to disrupt plant immunity. Nature 448:370-374.

Sakaguchi, A., Miyaji, T., Tsuji, G., and Kubo, Y. A. 2010. Kelch repeat protein, Cokellp, associates with microtubules and is involved in appressorium development in Colletotrichum orbiculare. Mol. PlantMicrobe Interact. 23:103-111.

Sambrook, J., Fritsch, E. F., and Maniatis, T. 1989. Molecular Cloning: A Laboratory Manual. Cold Spring Harbor Laboratory Press, Cold Spring Harbor, NY, U.S.A

Shen, S., Goodwin, P. H., and Hsiang, T. 2001. Infection of Nicotiana species by the anthracnose fungus Colletotrichum orbiculare. Eur. J. Plant Pathol. 107:763-773

Shirasu, K. 2009. The HSP90-SGT1 chaperone complex for NLR immune sensors. Annu. Rev. Plant Biol. 60:139-164.

Shirasu, K., and Schulze-Lefert, P. 2003. Complex formation, promiscuity and multi-functionality: Protein interactions in disease-resistance pathways. Trends Plant Sci. 8:252-258.

Stephenson, S. A., Hatfield, J., Rusu, A. G., Maclean, D. J., and Manners, J. M. 2000. CgDN3: An essential pathogenicity gene of Colletotrichum 
gloeosporioides necessary to avert a hypersensitive-like response in the host Stylosanthes guianensis. Mol. Plant-Microbe Interact. 13:929-941.

Sweigard, J., Chumley, F., Carrol, A., Farrall, L., and Valent, B. 1997. A series of vectors for fungal transformation. Fungal Genet. Newsl. 44:52-55.

Takano, Y., Oshiro, E., and Okuno, T. 2001. Microtubule dynamics during infection-related morphogenesis of Colletotrichum lagenarium. Fungal Genet. Biol. 34:107-121.

Takano, Y., Takayanagi, N., Hori, H., Ikeuchi, Y., Suzuki, T., Kimura, A., and Okuno, T. 2006. A gene involved in modifying transfer RNA is required for fungal pathogenicity and stress tolerance of Colletotrichum lagenarium. Mol. Microbiol. 60:81-92.

Takeda, A., Tsukuda, M., Mizumoto, H., Okamoto, K., Kaido, M., Mise, K., and Okuno, T. 2005. A plant RNA virus suppresses RNA silencing through viral RNA replication. EMBO (Eur. Mol. Biol. Organ.) J. 24:3147-3157.

Takken, F. L., Luderer, R., Gabriëls, S. H., Westerink, N., Lu, R., de Wit, P. J., and Joosten, M. H. 2000. A functional cloning strategy, based on a binary PVX-expression vector, to isolate HR-inducing cDNAs of plant pathogens. Plant J. 24:275-283.

Tanaka, S., Ishihama, N., Yoshioka, H., Huser, A., O'Connell, R., Tsuji, G., Tsuge, S., and Kubo, Y. 2009. The Colletotrichum orbiculare ssd mutant enhances Nicotiana benthamiana basal resistance by activating a mitogen-activated protein kinase pathway. Plant Cell 21:2517-2526.

Thomma, B. P., Nurnberger, T., and Joosten, M. H. 2011. Of PAMPs and effectors: The blurred PTI-ETI dichotomy. Plant Cell 23:4-15.

Thompson, J. D., Higgins, D. G., and Gibson, T. J. 1994. CLUSTAL W: Improving the sensitivity of progressive multiple sequence alignment through sequence weighting, position-specific gap penalties and weight matrix choice. Nucleic Acids Res. 22:4673-4680.
Vleeshouwers, V. G., Driesprong, J. D., Kamphuis, L. G., Torto-Alalibo, T., Van't Slot, K. A., Govers, F., Visser, R. G., Jacobsen, E., and Kamoun, S. 2006. Agroinfection-based high-throughput screening reveals specific recognition of INF elicitins in Solanum. Mol. Plant Pathol. 7:499-510.

Wang, Q., Han, C., Ferreira, A. O., Yu, X., Ye, W., Tripathy, S., Kale, S. D., Gu, B., Sheng, Y., Sui, Y., Wang, X., Zhang, Z., Cheng, B., Dong, S., Shan, W., Zheng, X., Dou, D., Tyler, B. M., and Wang, Y. 2011. Transcriptional programming and functional interactions within the Phytophthora sojae RXLR effector repertoire. Plant Cell 23:2064-2086.

Win, J., Kamoun, S., and Jones, A. M. 2011. Purification of effector-target protein complexes via transient expression in Nicotiana benthamiana. Methods Mol. Biol. 712:181-194.

Yaeno, T., Li, H., Chaparro-Garcia, A., Schornack, S., Koshiba, S., Watanabe, S., Kigawa, T., Kamoun, S., and Shirasu, K. 2011. Phosphatidylinositol monophosphate-binding interface in the oomycete RXLR effector AVR3a is required for its stability in host cells to modulate plant immunity. Proc. Natl. Acad. Sci. U.S.A. 108:14682-14687.

Zhang, M., Kadota, Y., Prodromou, C., Shirasu, K., and Pearl, L.H. 2010. Structural basis for assembly of Hsp90-Sgt1-CHORD protein complexes: Implications for chaperoning of NLR innate immunity receptors. Mol. Cell 39:269-281.

Zhao, X., Mehrabi, R., and Xu, J. R. 2007. Mitogen-activated protein kinase pathways and fungal pathogenesis. Eukaryot. Cell 6:1701-1714.

\section{AUTHOR-RECOMMENDED INTERNET RESOURCES}

SignalP analysis, http://www.cbs.dtu.dk/services/SignalP NetNGlyc1.0 server, http://www.cbs.dtu.dk/services/NetNGlyc 